\begin{tabular}{|c|c|c|c|c|c|c|}
\hline \multirow{4}{*}{ Impact Factor: } & ISRA (India) & $=3.117$ & SIS (USA) & $=0.912$ & ICV (Poland) & $=6.630$ \\
\hline & ISI (Dubai, UAE & $=0.829$ & РИНЦ (Russia) & $=0.156$ & PIF (India) & $=1.940$ \\
\hline & GIF (Australia) & $=0.564$ & ESJI (KZ) & $=8.716$ & IBI (India) & $=4.260$ \\
\hline & JIF & $=1.500$ & SJIF (Morocco) & $=5.667$ & OAJI (USA) & $=0.350$ \\
\hline
\end{tabular}

\section{SOI: $\underline{1.1 / \mathrm{TAS}}$ DOI: $10.15863 / \mathrm{TAS}$ International Scientific Journal Theoretical \& Applied Science}

p-ISSN: 2308-4944 (print) e-ISSN: 2409-0085 (online)

Year: 2019 Issue: $06 \quad$ Volume: 74

Published: $10.06 .2019 \quad \underline{\text { http://T-Science.org }}$
QR - Issue

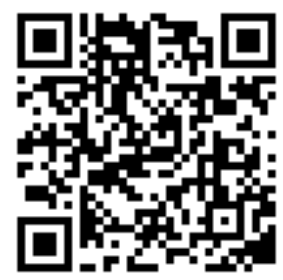

QR - Article

Aleksey Anatolievich Ivanov
Peter the Great St.Petersburg Polytechnic University
student
ahtunget@gmail.com

Vadim Andreevich Kozhevnikov

Peter the Great St.Petersburg Polytechnic University

Senior Lecturer

vadim.kozhevnikov@gmail.com

\title{
DESIGN AND DEVELOPMENT OF BLOOD DONORS RECORDING SYSTEM
}

Abstract: This work belongs to the sphere of web-development and process automation. Article considers existing electronic recording systems and analyses their functionality and advantages over others and determines the criteria by which the designed system should be better than existing. After that article describes choice of developer tools and methods and final testing of the application for potential donors and administrators.

Key words: blood donation, electronic record.

Language: English

Citation: Ivanov, A. A., \& Kozhevnikov, V. A. (2019). Design and development of blood donors recording system. ISJ Theoretical \& Applied Science, 06 (74), 1-6.

Soi: http://s-o-i.org/1.1/TAS-06-74-1 Doi: crossef https://dx.doi.org/10.15863/TAS.2019.06.74.1

\section{Introduction}

Today, automation and informatization affects all spheres of society and gradually information systems are present in almost every, even the smallest organization. The need to automatically take into account indicators, conveniently inform users, and also store information and have convenient and quick access to it has become more urgent than ever.

Following the successful results of the implementation and the global trend of informatization, in 2015, the initiative group of the St. Petersburg Polytechnic University transformed the action Donor Day in the information sphere. From a small event with a capacity of 100 people and passing once a year, it turned into the largest donor cell among the universities of St. Petersburg.

In many respects, this was possible due to the developed system of recording donors for delivery an electronic queue close to the hospital record, but due to the local features of the action with great functionality for the convenience of volunteers. In addition to the queue, a system for recording blood donations and mass preparation of documents for obtaining material assistance by volunteers was presented. According to the results, the action has grown and now only in two weeks passes about a thousand people through it.

Unfortunately, due to the huge rush the system turned out to be minimally viable. It is practically not adapted for use from a mobile device, uses outdated technologies, which greatly complicates the addition of new content and features, and also has many errors that appeared at the design level. And because of the nature of the preparation of documents and the specifics of the action itself, ready-made solutions are not possible to use, since their complete revision will be required, which will take a little less time than developing your own.

As a result, at the moment, it has ceased to meet the increased needs of Donor Day and has become the object of criticism from both volunteers and, from donors. From the above it follows that attempts to understand another's code and correct existing errors of the existing site, along with the problems described, are not possible. A fundamentally new development is needed, based on the old development rather in terms of design and some of the functionality, with global 


\begin{tabular}{llllll} 
& ISRA (India) $=\mathbf{3 . 1 1 7}$ & SIS (USA) & $=\mathbf{0 . 9 1 2}$ & ICV (Poland) & $=\mathbf{6 . 6 3 0}$ \\
Impact Factor: & ISI (Dubai, UAE) $=\mathbf{0 . 8 2 9}$ & PUHL (Russia) $=\mathbf{0 . 1 5 6}$ & PIF (India) & $=\mathbf{1 . 9 4 0}$ \\
& GIF (Australia) $=\mathbf{0 . 5 6 4}$ & ESJI (KZ) & $=\mathbf{8 . 7 1 6}$ & IBI (India) & $=\mathbf{4 . 2 6 0}$ \\
& JIF & $\mathbf{1 . 5 0 0}$ & SJIF (Morocco) $=\mathbf{5 . 6 6 7}$ & OAJI (USA) & $\mathbf{0 . 3 5 0}$ \\
\hline
\end{tabular}

processing of errors and the use of modern technologies.

\section{The purpose of the article}

The purpose of this work is to identify all the shortcomings and mistakes of the existing application and to develop a new system while retaining some of the best practices available. It must meet the increased requirements for the action of both donors and volunteers, as well as meet modern standards of design and development, have a simple and intuitive interface for simple users, which will attract new donors with convenience, and will not push aside incomprehensible functionality.

\section{Criteria definition}

To determine the relevance and the need to develop a new system, we highlight the main criteria with which it must meet and the necessary functionality to successfully replace the existing solution:

- low operating cost;

- flexibility in use;

- the possibility of maximum customization of all elements, as our system departs in its functionality from solutions offered by the service industry and business. The ideal option is an open-source project with a rich documentation and responsive community;

- security, since it implies the storage of personal data of donors.

Basic functionality that the system should have:

- create recording time;

- registration of donors, personal account;

- handwritten recording of donors, several people can sign up for the same time;

- display of basic information about the donor and his donations;

- delineation of the possibilities of donors depending on certain parameters that they have (role);

- the ability to print applications for material assistance in a pattern;

- the ability to expand and supplement the system with various software modules, built-in or not;

- differentiation of users by roles, during registration a person cannot register for some days depending on the specified data.

\section{Existing solutions research}

Today, we have a variety of solutions for recording and monitoring customers. Unfortunately, almost all of them belong to the commercial sphere and do not offer a system for volunteering and working with documents. In addition, the subject area under consideration is too narrow for us to be able to use a fully prepared system. Therefore, we will consider existing solutions that can best meet our criteria or can be integrated into a larger system.

Author reviewed 3 different existing systems, namely Get in line, MEDMIS and Hesus [1].
Medmis is the management system of your own clinic differs from the others by a lower threshold of entry, low cost and good adjustability of components. It allows you to organize the recording of patients for an appointment, set up an online recording form on the website, as well as work from any device, be it a desktop computer or a smartphone [2].

Get in line is a very popular service in the service sector, allowing you to automate work with clients and analyze business performance. It works as a separate component and does not require an existing site. In our case, it allows you to place the application code on your website and receive notifications about the registration of users for a certain time [3].

Hesus is an online recording designer with the ability to be placed on websites and social networking pages. It is used by such large companies as Afisha. In addition to the functionality, the service also sends notifications via SMS and e-mail, but SMS is charged separately and is not included in the tariff. The system interface is adaptive to the device and, like the others, provides its own embedded widget for sites and social networks [4].

The main drawback of all the above systems is the inconsistency of the capabilities of our business processes. Because of the narrow specifics specialized for the university, modules are needed that will process the necessary information in a manner unavailable to CRM systems.

It is also worth noting the vast possibility of improving the system in the future and adding a completely new functionality depending on the needs. No existing system can offer sufficient flexibility in modifying its code and components, with all its basic customization capabilities.

\section{Platform definition}

A web application is initially used as a platform, but theoretically the implementation of the system can also be presented as a classic application for personal computers running any popular operating system, as well as a mobile application. Highlight the main criteria of our system, which will affect the choice of platform:

- availability both for the user and for volunteers from any device anywhere in the city, because at any moment there may be a problem with incorrectly entered data that needs to be corrected or printed out of the next document;

- cross-platform, since the user must have access from a device with any operating system and architecture;

- convenience of work from a personal computer, as it is problematic and inconvenient to process large amounts of data, as well as print documents from a mobile device;

- since the access to user data should be not only for him, but also for volunteers, the application 


\begin{tabular}{llllll} 
& ISRA (India) $=\mathbf{3 . 1 1 7}$ & SIS (USA) & $=\mathbf{0 . 9 1 2}$ & ICV (Poland) & $=\mathbf{6 . 6 3 0}$ \\
Impact Factor: & ISI (Dubai, UAE) $=\mathbf{0 . 8 2 9}$ & PUHL (Russia) $=\mathbf{0 . 1 5 6}$ & PIF (India) & $=\mathbf{1 . 9 4 0}$ \\
& GIF (Australia) $=\mathbf{0 . 5 6 4}$ & ESJI (KZ) & $=\mathbf{8 . 7 1 6}$ & IBI (India) & $=\mathbf{4 . 2 6 0}$ \\
& JIF & $\mathbf{1 . 5 0 0}$ & SJIF (Morocco) $=\mathbf{5 . 6 6 7}$ & OAJI (USA) & $\mathbf{0 . 3 5 0}$ \\
\hline
\end{tabular}

must store them remotely on the server, and therefore work via the Internet.

The best option for us is a web application. At the moment it has a good reputation, and the technical problems of the system are not related to the platform used. The very same it satisfies all the above criteria, besides it has a number of its advantages [5]:

- does not require installation;

- cross-platform out of the box;

- access in any place where there is Internet; speed.

- one app for everything, high development

\section{Software architectural style}

At the moment there are two modern and actually used ways to adjust the interaction between the client and server part of the application, namely REST API and GraphQL. Both of them have gained a large fan base and are used in most modern applications. They are based on sending an HTTP request and receiving a response [6].

Due to its long history and support of developers of the main data transfer protocols on the Internet (HTTP), at the moment REST is the main architecture used in client-server architectures. Extensive community and documentation, as well as ease of development allows you to develop the API is quite convenient and simple, and most importantly, quickly and efficiently, there is no need to master complex technologies besides REST itself.

GraphQL does not yet have such an extensive community, is difficult to master at first, although it is very convenient and functional, if you could already master it, but it is not sufficiently self-sufficient, therefore, in choosing the architecture of interaction of application components, we will focus on REST architecture We will make a RESTful API.

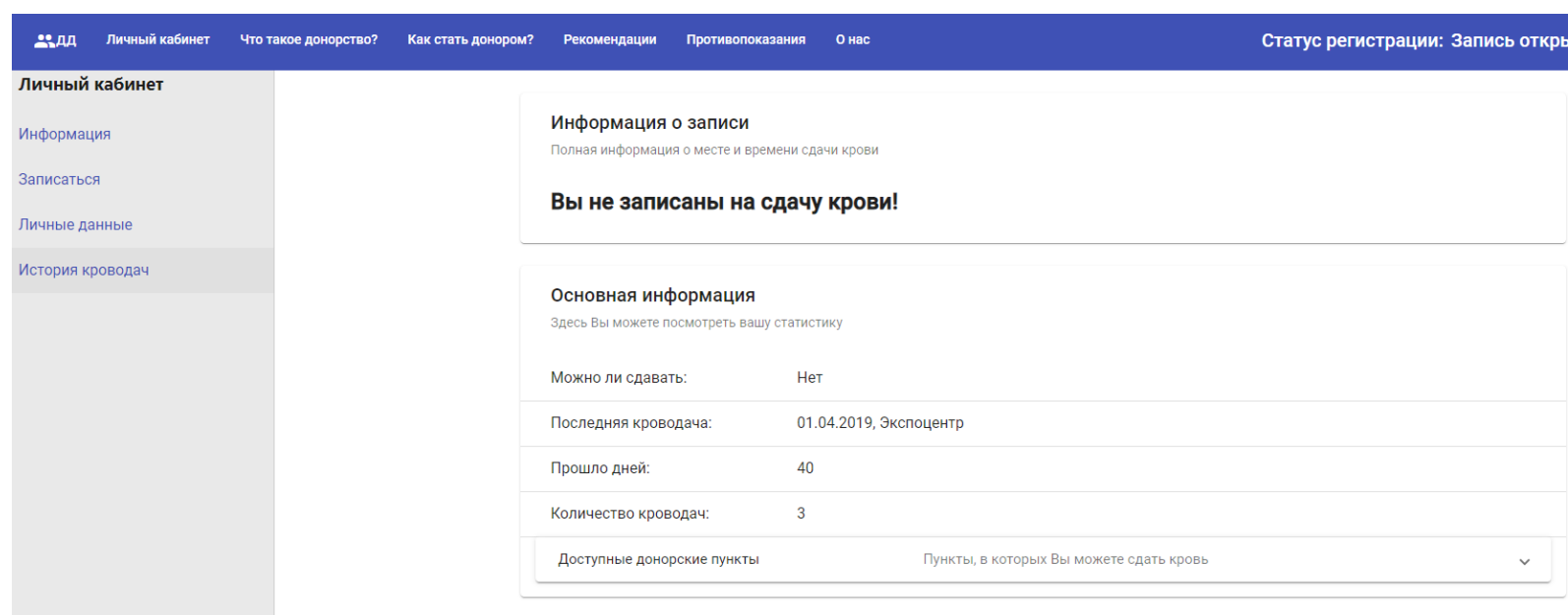

Figure 1 - Personal cabinet

\section{Client side}

For the client part of almost any web application, at present, standard CSS3 binding (and SASS / SCSS preprocessors for it), HTML5 and JavaScript are used. The main distinguishing feature and subject of choice is the framework for JavaScript, which will allow you to increase development speed several times and will provide basic functionality for creating a modular application that you will not have to write yourself. Currently, there are three giants on the market: React, Vue and Angular, which form the basis of most web applications and are frameworks with a large base and community support, as well as the most productive and easy to use, so the choice will be made from them [7].

For small projects, the ideal solution is Vue, which allows you to create prototypes as soon as possible, or React with a small threshold of entry. In our case, when the project claims some global and average size, with proper skills, the best option would be Angular.

In addition, the main criterion for choosing a framework is always which one will be easier for developers to study before being able to fully develop an application. In our case, almost the annual experience of development on Agular leaves no alternatives to the others.

\section{Server side}

For the server part at the moment there are many different platforms on which you can implement the server part of web applications from both large corporations and independent developers. To determine the direction in which to consider them, and 


\begin{tabular}{llllll} 
& ISRA (India) $=\mathbf{3 . 1 1 7}$ & SIS (USA) & $=\mathbf{0 . 9 1 2}$ & ICV (Poland) & $=\mathbf{6 . 6 3 0}$ \\
Impact Factor: & ISI (Dubai, UAE) $=\mathbf{0 . 8 2 9}$ & PUHL (Russia) $=\mathbf{0 . 1 5 6}$ & PIF (India) & $=\mathbf{1 . 9 4 0}$ \\
& GIF (Australia) $=\mathbf{0 . 5 6 4}$ & ESJI (KZ) & $=\mathbf{8 . 7 1 6}$ & IBI (India) & $=\mathbf{4 . 2 6 0}$ \\
& JIF & $\mathbf{1 . 5 0 0}$ & SJIF (Morocco) $=\mathbf{5 . 6 6 7}$ & OAJI (USA) & $\mathbf{0 . 3 5 0}$ \\
\hline
\end{tabular}

narrow down the range of languages and frameworks, we will determine the criteria that they must meet:

- lightness - the platform should not take much space and server resources, as for this application it is simply unnecessary, because the main server activity will not be in complex calculations, besides, the system will not be highly loaded;

- good documentation and a large community, as reference information is needed if development difficulties arise;
- development speed, since we need a fullfledged application in a short time, in which it is necessary to create all three levels, then the development speed is critical;

- low threshold of entry, since if the experience of developing the server side of the application is less, then taking languages with a high threshold of entry is disproportionate to the final result.

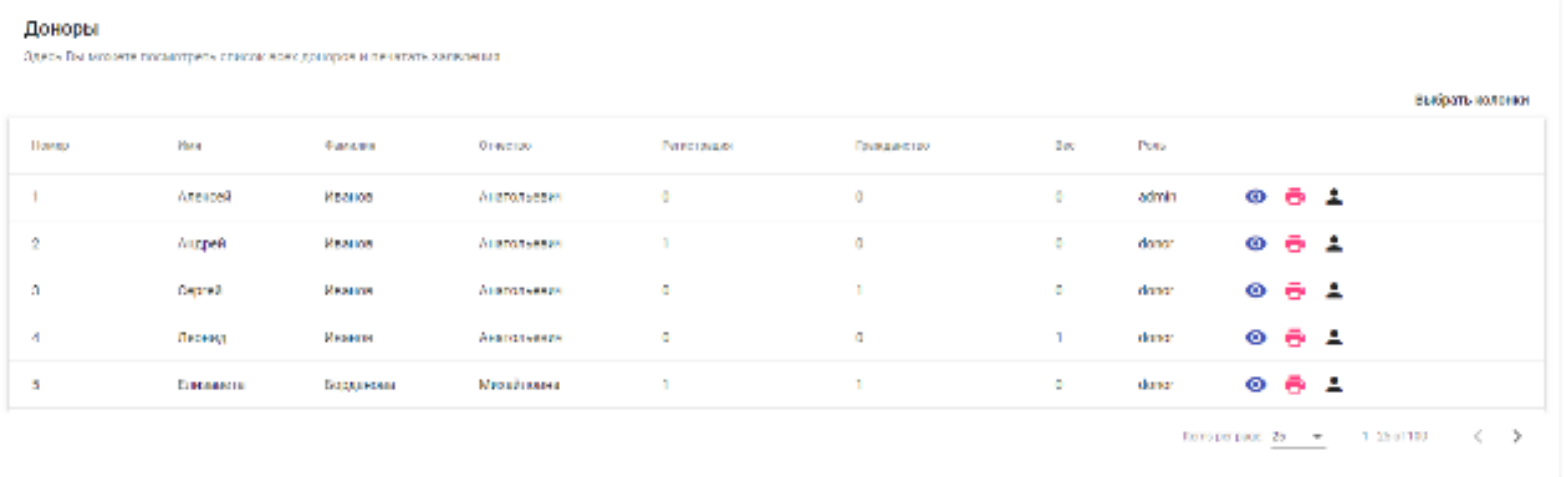

Figure 2 - Administrative panel

As a result, we have that according to many criteria powerful languages like C\# and Java do not suit us, because, despite the experience of development, they occupy a huge amount of space and resources that are completely unnecessary within the framework of this application.

The best option is Node.js, a software platform for JavaScript whose kernel is written in C++. It is developing very fast and is the main trend of recent years, the JS language occupies the first lines of the most popular rankings, and also supports out-of-date asynchrony from the latest versions. There are a lot of libraries written for the language, which can be safely used both on the client side (about this in the next paragraph) and on the server side. In addition, because of all of the above, Node.js has a very large community that is ready to give answers to any question [8]. It also manages a large number of asynchronous requests and simple calculations.

\section{Data Base}

To date, the market provides many DBMS that satisfy various user requests, from large applications to local applications, like ours. When choosing a database, we will build on the following criteria:

- Free solution, since the financing of the action itself is minimal and will not be able to cover the maintenance of the paid base without affecting the other components.

- Ease of use, design and maintenance, as there are no full-fledged IT specialists in the action, the base must have an intuitive graphical interface so that in the future an inexperienced administrator can correct critical bugs.

- Security and reliability, since the personal data of each participant is stored in the system, the probability of information leakage should be minimal.

- Providing ACID (Atomicity, Consistency, Isolation, Durability) to avoid errors on the server and client side during CRUD operations, as there are many participants in the system and there were no documents when printing inaccuracies. In addition, all donor data will be stored for a long time. 


\begin{tabular}{llllll} 
& ISRA (India) $=\mathbf{3 . 1 1 7}$ & SIS (USA) & $=\mathbf{0 . 9 1 2}$ & ICV (Poland) & $=\mathbf{6 . 6 3 0}$ \\
Impact Factor: & ISI (Dubai, UAE) $=\mathbf{0 . 8 2 9}$ & PUHL (Russia) $=\mathbf{0 . 1 5 6}$ & PIF (India) & $=\mathbf{1 . 9 4 0}$ \\
& GIF (Australia) $=\mathbf{0 . 5 6 4}$ & ESJI (KZ) & $=\mathbf{8 . 7 1 6}$ & IBI (India) & $=\mathbf{4 . 2 6 0}$ \\
& JIF & $\mathbf{1 . 5 0 0}$ & SJIF (Morocco) $=\mathbf{5 . 6 6 7}$ & OAJI (USA) & $\mathbf{0 . 3 5 0}$ \\
\hline
\end{tabular}

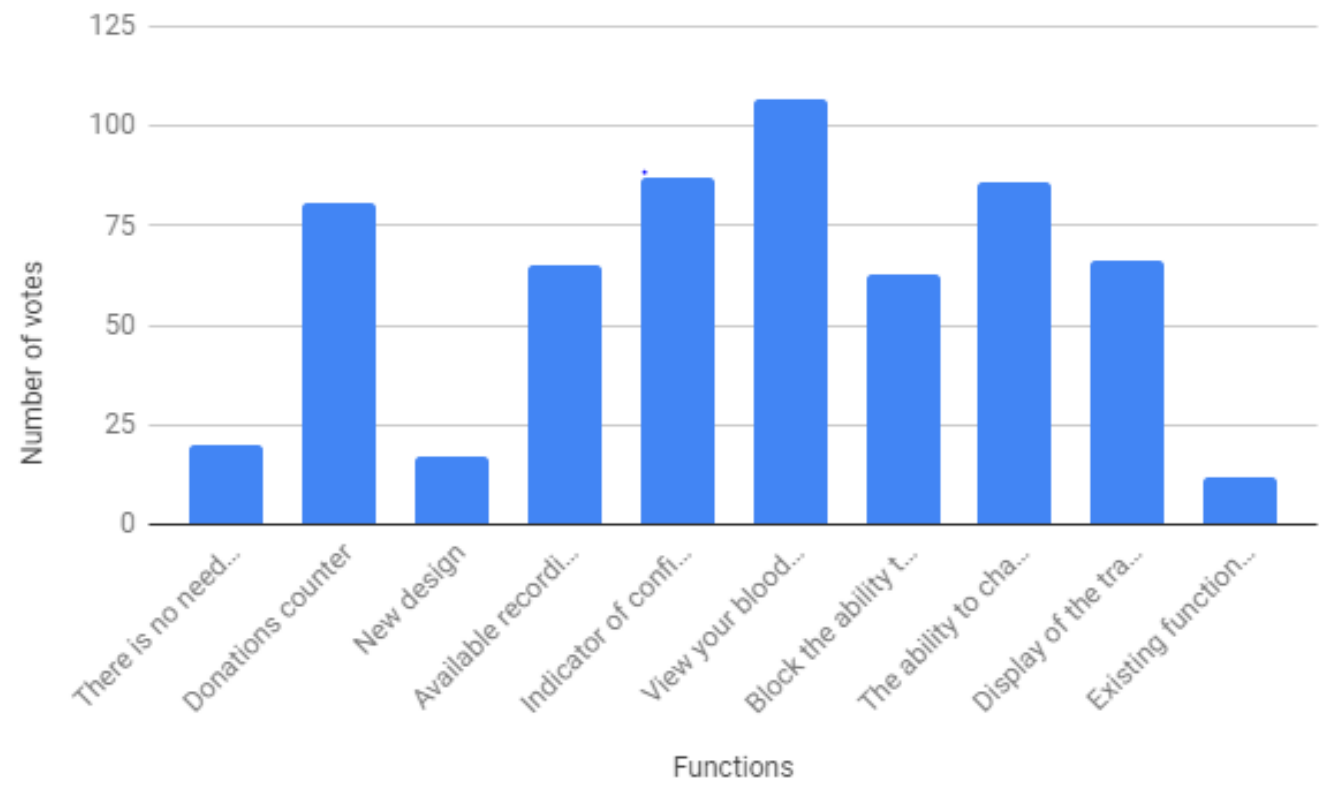

Figure 3 - User part approval bar graph

Based on the first criterion, we discard paid solutions like the Oracle Database, and according to the last criterion, non-relational databases will not suit us, since they do not satisfy ACID, the data itself can be stored separately and without external logical connections. Consider non-relational databases as soon as possible in terms of authentication by the token stored in them.

MySQL is the most popular free full-fledged server database. Due to its popularity, there are many plug-ins and extensions for it. It successfully works with sites and web applications, has a simple intuitive graphical interface [9]. She has an active community and a lot of usage information. MySQL supports most of the SQL functionality required for a web application, has a large number of security features, which is critical in our situation, and also has a high speed. Among the shortcomings, it is worth noting some unreliability of the part of data processing methods and some reasonable limitations envisaged by the developers.

\section{Application}

Here we will look at system testing on users who dealt with the current version of the system. Based on the implemented functionality, we will highlight the main distinctive points for which we will build statistics and determine which points users liked most, which are less and whether the new version suits them in terms of functionality and design.
To evaluate the user part, the following survey was created in the main group of the social network VKontakte of the Donor Day [10] campaign, in which donors take part directly using the current version of the application. For this, the following highlights of the new system were highlighted and the following questions were put together.

A. There is no need to fill in the fields with documents to self-funded students.

B. Donations counter.

C. New design.

D.Available recording time depending on registration, citizenship and weight.

E. Indicator of confirmation of your record in your account.

F. View your blood donation history (transfusion point, date).

G. Block the ability to enroll if a short time has passed since the last blood donation.

$\mathrm{H}$. The ability to change the time of submission before approval without having to write to anyone.

I. Display of the transfusion point when recording in your account.

J. Existing functionality is enough.

The survey participants at the time of data collection turned out to be 165 . Respondents were allowed to vote for any number of points that satisfy them the most.

As we can see, respondents generally welcome the new functionality (93\%). Most of all, they like 


\begin{tabular}{|c|c|c|c|c|c|c|}
\hline \multirow{4}{*}{ Impact Factor: } & ISRA (India) & $=3.117$ & SIS (USA) & $=0.912$ & ICV (Poland) & $=6.630$ \\
\hline & ISI (Dubai, UAE & $=0.829$ & РИНЦ (Russia) & $=0.156$ & PIF (India) & $=1.940$ \\
\hline & GIF (Australia) & $=0.564$ & ESJI (KZ) & $=8.716$ & IBI (India) & $=4.260$ \\
\hline & JIF & $=1.500$ & SJIF (Morocco) & $=5.667$ & OAJI (USA) & $=0.350$ \\
\hline
\end{tabular}

such functions as: viewing the history of their blood supply $(65 \%)$, indicator of confirmation of your transfer record in the personal account (53\%), as well as the ability to change the time of submission before approval without having to write to someone (52\%). To a lesser extent, users will pay attention to the updated design (10\%) and indicated that they have enough existing functionality (7\%). Also, due to the small number of contractual donors, we observe a lack of interest in the absence of the need to fill out the document fields for students with a contractual form of education (12\%).

\section{Conclusion}

The developed application meets all the requirement. It is ergonomic, easy and satisfies the basic needs of the consumer. Moreover, it is not inferior to competitors in the market and even surpasses some of them in functionality. Conclusions about the choice of tools can be used when designing similar applications.

\section{References:}

1. (n.d.). Scheduling services and customer records [online] Retrieved May 02, 2019, from https://startpack.ru/category/appointments-andscheduling

2. (n.d.). MEDMIS [online] Retrieved May 15, 2019, from https://www.medmis.ru

3. (n.d.). Get in line [online] Retrieved May 13, 2019, from https://get-in-line.ru

4. (n.d.). Hesus. [online] Retrieved May 15, 2019, from https://hesus.ru/

5. (2007). Belliniaso. Razrabotka Web-prilozhenij $\mathrm{v}$ srede ASP.NET 2.0: zadacha - proekt reshenie. (p.640). Moscow: Dialektika.

6. Stubailo, S. (2017). GraphQL vs. REST [online] Retrieved June 02, 2019, from https://blog.apollographql.com/graphql-vs-rest5d425123e34b

7. Ulitovskij, A. (2019). Sravnenie JavaScript frejmvorkov Vue.js, React i Angular, 2019 [online] Retrieved April 15, 2019, from https://mkdev.me/posts/sravnenie-javascriptfreymvorkov-vue-js-react-i-angular-2019

8. Mardan, A. (2014). Practical Node.js: Building Real-World Scalable Web Apps. 1st ed. (p.300). New-York: Apress.

9. (n.d.). Why MySQL? [online] Retrieved May 05, 2019, from https://www.mysql.com/why-mysql/

10. (n.d.). Den' donora [online] Retrieved May 10, 2019, from https://vk.com/polydonor 